\title{
Tecnologias digitais para tornar visíveis informações sócio-espaciais
} Digital technologies to make socio-spatial information visible

\author{
Maria Laura Vilhena \\ Lagear e MOM - UFMG, Brasil \\ marialauravds@gmail.com
}

Ana Paula Baltazar

Lagear e MOM - UFMG, Brasil

baltazar.ana@gmail.com

Ana Paula Pitzer

Lagear e MOM - UFMG, Brasil

ana.pitzer@hotmail.com

\section{Camila Oddi Duran}

Lagear e MOM - UFMG, Brasil

milagome3@gmail.com

\author{
Larissa Reis \\ Lagear e MOM - UFMG, Brasil \\ laguireis@gmail.com \\ Maria Cecília Rocha \\ Lagear e MOM - UFMG, Brasil \\ mceciliarcgomes@gmail.com \\ Marllon Morais \\ Lagear e MOM - UFMG, Brasil \\ marllonlom@gmail.com
}

\begin{abstract}
This paper discusses the association of SPSS, combined to Google Forms, and GEPHI in the context of a socio-spatial data collection in Glaura (a district of Ouro Preto/MG - Brazil), for the development of a technical advisory method using interfaces. It also describes the steps of using these softwares, their potentials, the difficulties found throughout the process, and the qualitative analysis based on the graphic and tabular results of the data. The main goal is to make visible complex information about the socio-spatial relations within the community to further use it to inform the conception of interfaces.
\end{abstract}

Keywords: Assessoria técnica; Interfaces; Tecnologias digitais; Análise qualitativa.

\section{Introdução}

Um método de assessoria técnica de arquitetura e urbanismo para comunidades frágeis vem sendo estruturado pelos grupos LAGEAR (Laboratório Gráfico para Experimentação Arquitetônica) e MOM (Morar de Outras Maneiras) desde 2015 na Universidade Federal de Minas Gerais. As pesquisas dos dois grupos vinham apontando atuações pouco efetivas dos arquitetos, reproduzindo processos autoritários em comunidades frágeis, seja como no caso da atuação tecnocrática (usual entre os técnicos de prefeituras), pela adesão a procedimentos prescritos e impostos de cima para baixo; seja pela atitude de boa fé e boa vontade, chamada de missionária, que impõe na comunidade a cultura de classe média dos arquitetos, levantando problemas a partir de seu próprio olhar, sem de fato entender as demandas vindas dos moradores; seja por uma atuação artística, autoral, que toma a comunidade como pano de fundo para a autopromoção (KAPP et al, 2012). Essas atuações são reforçadas pela lógica assistencialista, oficializada pela lei de assistência técnica que "assegura às famílias de baixa renda assistência técnica pública e gratuita para o projeto e a construção de habitação de interesse social" (BRASIL, 2008). Tal lei é baseada na lógica de assistência à saúde (SUS), acentuando a separação entre conhecimento técnico e prestação de serviço, de um lado, e comunidade usuária de outro. No caso da produção do espaço, tal separação é danosa, visto que os usuários sabem muito mais sobre seus espaços que os técnicos e se faz necessário repensar a relação entre conhecimento técnico e conhecimento leigo.

Ivan Illich (1968) critica a relação assistencialista falando aos voluntários norte-americanos que "venham para ver, venham para escalar nossas montanhas e apreciar nossas flores [...], mas não venham ajudar". Illich (1990) argumenta que a percepção das necessidades de um grupo é muitas vezes relativa a um modelo de consumo de outro grupo e não a carências de fato. Isso é facilmente perceptível quando estudantes de arquitetura vão pela primeira vez a uma favela e, sem conversar com nenhum morador, inferem que o maior problema da favela é falta de ventilação e iluminação. A percepção dos estudantes é moldada por seu modo de vida sem considerar que outras prioridades podem pautar o modo de vida dos moradores da favela. Essa atitude enquadra-se claramente na postura assistencialista, que tentamos combater.

Baltazar e Kapp (2016) distinguem assistência de assessoria dizendo que

"há uma diferença relevante entre prestar assistência na perspectiva de que as pessoas se adaptem cada vez melhor a um padrão prescrito de necessidades e satisfações ou, inversamente, buscar uma assessoria na perspectiva de que consigam articular suas próprias demandas e orquestrar, com autonomia crescente, [como] satisfazê-las" (Baltazar e Kapp, 2016). 
As autoras apontam a assessoria como ideal a ser alcançado na relação de arquitetos e urbanistas com grupos sócioespaciais.

Com base nessa proposta de atuação, o método de assessoria técnica que estamos desenvolvendo tem por objetivo a emancipação de grupos sócio-espaciais, lançando mão de estratégias de atuação que visam a construção de uma autonomia coletiva, de modo a evitar a criação de relações de dependência entre técnicos e comunidade. Para isso recorremos à produção de interfaces (digitais, físicas ou híbridas) como instrumentos de mediação específicos para assessorar tecnicamente o grupo sócio-espacial em questão, além de articulá-los dialogicamente para a tomada de decisões sobre o espaço. O papel das interfaces na assessoria técnica é fundamental para viabilizar algumas diretrizes discutidas por Baltazar e Kapp (2016), quais sejam:

"uma assimetria assumida entre técnicos e assessorados em vez de uma pretensa simetria; a abertura para algum ganho de autonomia, individual e coletiva, em vez da criação de novas dependências; a ampliação do imaginário acerca do espaço e de sua produção em vez da adesão a pressupostos abstratos e soluções técnicas que ainda desqualificam conhecimentos e práticas dos assessorados; e a rearticulação de uma esfera pública, diferente tanto da esfera privada, quanto da esfera social (Arendt, 2011), ou, em outros termos, uma retomada do político" (Pogrebinschi, 1999).

Em oposição ao usual processo participativo que prescreve uma sequência de passos a ser seguida pelos usuários numa tentativa de engajá-los em algo que não é orientado por suas práticas cotidianas (KAPP e BALTAZAR, 2012), é fundamental que as informações e conhecimentos dos próprios moradores sejam tomados como ponto de partida para a criação de interfaces. Assim, faz-se necessário, além de um levantamento sócio-espacial, tornar visíveis as informações coletadas para uma primeira análise, no processo de produção das interfaces que pretendem articular o grupo sócio-espacial nas tomadas de decisão.

Para o desenvolvimento concreto do método, elegemos um grupo sócio-espacial para estudo de caso. Um grupo sócioespacial é mais que um grupo social que tem um mesmo espaço como pano de fundo (como uma cidade grande, por exemplo); é considerado um grupo que constitui o espaço e é constituído por ele. Assim, dificilmente uma cidade grande pode ser considerada um grupo sócio-espacial. Contudo, o que o define não é seu tamanho ou território, mas o grau de articulação entre sociedade e espaço. O grupo sócioespacial escolhido para iniciarmos nosso estudo foi Glaura, distrito de Ouro Preto (Brasil), por se tratar de uma comunidade de aproximadamente 1400 habitantes que claramente constitui e é constituída pelo espaço e atualmente enfrenta um processo lento e contínuo de gentrificação em que é perceptível uma certa apatia dos moradores.

Glaura é bastante particular pois, se por um lado a comunidade vem resistindo (à sua maneira) às tentativas de gentrificação que têm ocorrido em seu território, por outro, quando a iniciativa heterônoma é violenta, a comunidade tende a ser atropelada. Já há alguns anos, Glaura vem sofrendo um processo de gentrificação lento e silencioso. Muitas casas da comunidade foram vendidas por valores altos e atualmente alguns membros da comunidade já ressentem que aproximadamente $30 \%$ das moradias tornaram-se casas de final de semana, com todos os problemas que isso pode gerar para o cotidiano de uma comunidade. Contudo, os moradores não foram expulsos da comunidade, apenas venderam suas casas e construíram novas moradias fora do centro histórico, mas ainda muito próximas e com condições razoáveis. Esse processo vem acontecendo lentamente, casa por casa, sendo que atualmente os moradores já formulam por si mesmos uma crítica a tal situação que se assemelha à gentrificação. Por outro lado, uma iniciativa totalmente heterônoma de empresários com a empreendedora EPO e o arquiteto Gustavo Penna, está em andamento para a implantação de um empreendimento de grande porte (maior que a própria comunidade), sem que sejam discutidos com os moradores seus possíveis impactos. São propostos 900 lotes de 1.500 $\mathrm{m}^{2}$, ou seja, um empreendimento exclusivo para classe média, na entrada de Glaura, segregando ainda mais os moradores que ainda resistem no centro histórico. Houve audiência pública para discutir o empreendimento, mas não foram discutidos seus impactos no futuro da comunidade. Não foi levantada a hipótese sobre o tamanho dos lotes ser indutor de apenas uma faixa de renda, nem sequer foram aventadas as hipóteses sobre onde vão morar os trabalhadores da construção civil (que não terão condições de morar no loteamento) e acabarão impactando fortemente a comunidade.

Ainda que os moradores tenham uma forte relação de vizinhança e solidariedade, há uma clara apatia e falta-lhes estímulo e informação para que sejam capazes de prospectar seu futuro, conforme nos aponta Jessé Souza (2009), pois os impactos do processo de gentrificação no seu grupo sócio-espacial estão fora de seu cotidiano. A vida pacata que lhes é tão cara tende a ser destruída caso não se articulem para entender o processo que lhes está sendo imposto de fora e sejam capazes de tomar decisões autonomamente.

O processo de gentrificação em andamento em Glaura, aliado a um desejo de articulação da associação comunitária do distrito, nos pareceu bastante propício para trabalharmos - método de assessoria técnica. Assim, começamos a frequentar Glaura com estudantes de graduação em 2015 e foram feitas as primeiras aproximações da comunidade visando entender como lidam com os espaços, seguidas de intervenções urbanas interativas efêmeras que lidavam com algumas das questões espaciais levantadas. A comunidade foi bastante receptiva às intervenções efêmeras nos dois semestres e começamos então a aprofundar nosso entendimento do local.

Em uma primeira etapa de levantamento mais sistemático, para além do trabalho com estudantes de graduação, foram feitas entrevistas semi-estruturadas que embasaram a elaboração de um questionário quali-quantitativo minucioso com a proposta de aprofundar o entendimento das relações sócio-espaciais desse grupo. 
Com o objetivo de levantar a maioria dos domicílios da comunidade, foi proposta a disciplina optativa "Levantamento sócio-espacial em Glaura" no curso de graduação em Arquitetura e Urbanismo da UFMG em que os alunos matriculados, após aulas iniciais (em que se discutiu a usual atuação dos arquitetos em comunidades frágeis, introduziram-se conceitos, tais como assessoria e pesquisa quali-quantitativa, e apresentaram-se o caso de Glaura, o questionário e os softwares a serem utilizados), aplicaram o questionário em aproximadamente 200 unidades habitacionais. Esse questionário foi composto por aproximadamente 60 perguntas contemplando tanto questões baseadas no censo IBGE acerca da escolaridade, trabalho, idade, cor/raça, deficiência e renda dos moradores, quanto perguntas que retomavam assuntos já apontados nas entrevistas semi-estruturadas sobre as relações entre os moradores, trabalho de reprodução, compreensão histórica e cultural do distrito, saneamento e percepções das mudanças recentes. As respostas às questões variam entre abertas, fechadas e enumerativas e a necessidade de sistematizar a grande quantidade de dados instigou o uso do software SPSS (Statistical Package for the Social Sciences) da IBMAnalytics para tabulação, cruzamento e elaboração de gráficos, que nos permitiria compilar os dados levantados e analisar os padrões de ocorrência.

São apresentados a seguir o processo de utilização do SPSS e sua associação com o Formulários Google (Google Forms) para sistematização das informações dos questionários e a posterior análise dos dados e cruzamentos obtidos no contexto do levantamento sócio-espacial da comunidade de Glaura.

\section{SPSS E FORMULÁRIOS}

Em uma primeira aproximação com o SPSS foi possível perceber que sua curva de aprendizagem não seria compatível com curto prazo da disciplina e, principalmente, que seria inviável compatibilizar uma grande quantidade de questionários compilados por pessoas diferentes no mesmo arquivo. Dessa forma, de modo a otimizar o processo de tabulação, buscamos associar o uso do SPSS ao Formulários Google, que faz parte de um pacote de aplicativos, fornecido pela Google Inc., e possibilita a criação de uma enquete online com as perguntas do questionário e a sistematização das respostas em uma planilha, gerando gráficos em tempo real. Para a elaboração da enquete online foi necessário reescrever as perguntas do questionário usando o editor do Formulários Google e adaptar as ferramentas de seleção que o aplicativo oferece para os tipos de respostas obtidas na aplicação dos questionários. Finalizada essa etapa, o link da enquete foi enviado aos alunos para que preenchessem de acordo com as respostas obtidas no trabalho de campo.

De modo geral o uso do aplicativo foi bastante vantajoso nesse contexto, principalmente por se tratar de uma plataforma online, gratuita e bastante intuitiva e permitir o preenchimento simultâneo por diversos usuários, contrapondo-se ao SPSS que, por sua vez, é um software pago, de difícil acesso, manipulação e preenchimento por múltiplos usuários. Além disso, a criação automática de uma planilha única, a partir do Formulários Google, com as respostas obtidas facilitou a visualização, a manipulação dos dados e a sua inserção no SPSS pela equipe de pesquisadores.

Um dos problemas observados, no entanto, foi a falta de correspondência entre a linguagem da planilha gerada no Formulários Google, cujas respostas eram frases por extenso, e a linguagem do SPSS, que utiliza variáveis numéricas em sua tabulação. Isso demandou uma uniformização das respostas dos questionários, de forma a gerar variáveis coerentes para a manipulação estatística. Outro ajuste realizado foi a separação em colunas das respostas múltiplas, para que fossem lidas cada uma como uma variável no momento em que a planilha exportada no formato CSV (extensão .csv - Comma-Separated Values) fosse aberta no SPSS.

O passo seguinte foi criar um template no SPSS que continha a listagem das variáveis correspondentes às perguntas dos questionários e seus valores numéricos associados às respostas por extenso. Além disso, foi necessário classificar essas variáveis em dois tipos: ordinais, mensuradas em unidades de medida (renda familiar, idade etc.), e nominais ou categóricas, mensuradas em categorias (sexo, profissão, religião, cidade natal etc.).

Ao inserir nesse template as informações da planilha, obtémse um banco de dados, em forma de matriz, em que as linhas correspondem às respostas de cada entrevistado e as colunas, às perguntas do questionário. Depois de compilar as informações obtidas e com o objetivo de cruzá-las, é necessário, em um primeiro momento, examinar separadamente cada variável do banco de dados, a fim de obter as frequências simples de cada resposta e, com isso, uma visão geral dos resultados do questionário. Para realizar esses exames foram utilizadas tabelas de frequências simples geradas a partir dos comandos "Analyze" seguido por "Descriptive Statistics" e "Frequencies". Selecionada a variável desejada, obtém-se automaticamente uma tabela, que indica as respostas, em valores relativos ("Porcentagem \%") e absolutos ("Contagem"), discriminando-as em válidas (ou respondidas) e ausentes, conforme mostra a figura 1.

\begin{tabular}{|c|c|c|c|}
\hline & & Contagem & Porcentagem \% \\
\hline \multirow[t]{11}{*}{ Válido } & Glaura & 52 & 12,5 \\
\hline & Centro & 5 & 1,2 \\
\hline & Casa Branca & 24 & 5,8 \\
\hline & Campo & 60 & 14,5 \\
\hline & Soares & 45 & 10,8 \\
\hline & Prainha & 1 & ,2 \\
\hline & Alto de Glaura & 1 & ,2 \\
\hline & Campo de Glaura & 3 & ,7 \\
\hline & Distrito & 1 & ,2 \\
\hline & Total & 192 & 46,3 \\
\hline & Ausente & 223 & 53,7 \\
\hline Total & & 415 & 100,0 \\
\hline
\end{tabular}

Figura 1: Saída do SPSS em forma de tabela para as frequências simples da pergunta "Como você chama essa região em que você mora". 
Extraídas as frequências simples, foram iniciados os cruzamentos entre duas variáveis, principalmente entre as nominais ou categóricas, visto que são mais presentes no questionário. A tabulação cruzada é possível utilizando o comando "Crosstabs", seguido da seleção das variáveis escolhidas, gerando automaticamente as tabelas e gráficos. Essas tabelas e gráficos relacionam as respostas de cada pergunta entre si e expõem os valores relativos e absolutos de cada combinação possível. O cruzamento das informações da tabulação justifica-se no contexto desse levantamento por associar os diferentes conteúdos abordados pelos questionários, evidenciando aspectos quantitativos antes não visíveis, permitindo análises qualitativas mais aprofundadas sobre o contexto sócioespacial do distrito de Glaura.

Como você chama essa regiāo em que você mora? $\mathbf{X}$ Você tem alguma reclamação sobre $\mathbf{a}$ água utilizada?

\begin{tabular}{|c|c|c|c|c|c|}
\hline & & & \multicolumn{2}{|c|}{$\begin{array}{l}\text { Você tem alguma reclamação } \\
\text { sobre a água utilizada? }\end{array}$} & \multirow[b]{2}{*}{ Total } \\
\hline & & & Não & Sim & \\
\hline \multirow{18}{*}{$\begin{array}{l}\text { Como você chama essa } \\
\text { região em que você mora? }\end{array}$} & Glaura & Contagem & 17 & 35 & 52 \\
\hline & & $\%$ do Total & $8,9 \%$ & $18,2 \%$ & $27,1 \%$ \\
\hline & Centro & Contagem & 4 & 1 & 5 \\
\hline & & $\%$ do Total & $2,1 \%$ & $0,5 \%$ & $2,6 \%$ \\
\hline & Casa Branca & Contagem & 4 & 20 & 24 \\
\hline & & $\%$ do Total & $2,1 \%$ & $10,4 \%$ & $12,5 \%$ \\
\hline & Campo & Contagem & 15 & 45 & 60 \\
\hline & & $\%$ do Total & $7,8 \%$ & $23,4 \%$ & $31,3 \%$ \\
\hline & Soares & Contagem & 6 & 39 & 45 \\
\hline & & $\%$ do Total & $3,1 \%$ & $20,3 \%$ & $23,4 \%$ \\
\hline & Prainha & Contagem & 0 & 1 & 1 \\
\hline & & $\%$ do Total & $0,0 \%$ & $0,5 \%$ & $0,5 \%$ \\
\hline & Alto de Glaura & Contagem & 0 & 1 & 1 \\
\hline & & $\%$ do Total & $0,0 \%$ & $0,5 \%$ & $0,5 \%$ \\
\hline & Campo de Glaura & Contagem & 0 & 3 & 3 \\
\hline & & $\%$ do Total & $0,0 \%$ & $1,6 \%$ & $1,6 \%$ \\
\hline & Distrito & Contagem & 0 & 1 & 1 \\
\hline & & $\%$ do Total & $0,0 \%$ & $0,5 \%$ & $0,5 \%$ \\
\hline \multirow[t]{2}{*}{ Total } & & Contagem & 46 & 146 & 192 \\
\hline & & $\%$ do Total & $24,0 \%$ & $76,0 \%$ & $100,0 \%$ \\
\hline
\end{tabular}

Figura 2. Saída do SPSS em forma de tabela cruzada entre a região onde mora e reclamação sobre a água utilizada.

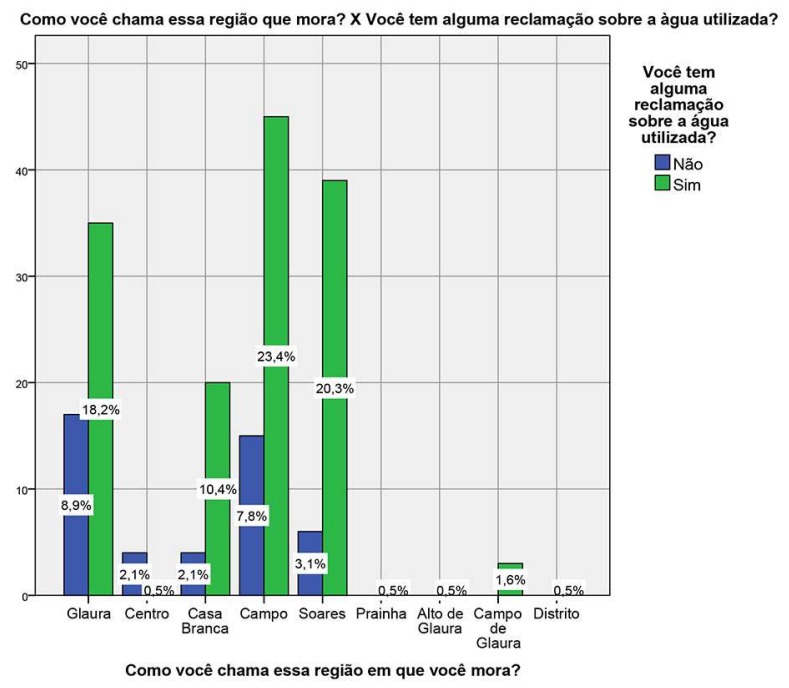

Figura 3. Gráfico do cruzamento entre a região onde mora e reclamação sobre a água utilizada.
É possível dizer que a utilização do SPSS possibilitou rapidez no cruzamento das informações e geração de gráficos e tabelas e, por isso, à medida que foram feitas as análises, foram feitos novos cruzamentos de acordo com as demandas e questionamentos que surgiam durante 0 processo. Na elaboração dos gráficos, a preocupação foi tornar os dados legíveis, para que cumprissem sua função de comunicar as ideias complexas com clareza, precisão e eficiência (TUFTE, 1983). Considerando o contexto do levantamento sócio-espacial detalhado como pretendido, tais gráficos devem tornar esses cruzamentos compreensíveis de modo que quem vai fazer a análise possa entender os dados em diferentes níveis de detalhe, desde uma visão geral até uma mais específica, possibilitando, também, comparar os dados entre os gráficos feitos no estudo. Uma das principais dificuldades enfrentadas, no entanto, foi diagramar os gráficos com a quantidade de dados e variáveis que continham utilizando as ferramentas de personalização da saída do gráfico no SPSS, que, por exemplo, não permitiam alterar livremente a posição dos textos e tamanho das fontes. As figuras 2 e 3 são exemplo do que é possível extrair do SPSS usando cruzamento de dados, tanto em forma de tabelas com contagens absolutas e relativas, quanto para gerar gráficos que facilitem a visualização. Contudo, alguns gráficos com maior quantidade de informação ficaram ilegíveis nas figuras de saída do programa e, para corrigi-los, utilizamos softwares de edição de imagens.

\section{Análise qualitativa de dados quantitativos}

A partir, então, das frequências simples (exemplificadas na figura 1) e dos dados cruzados (exemplificados nas figuras 2 e 3) teve início o processo de análise dessas informações, do qual participaram tanto os pesquisadores quanto os alunos da disciplina. Aos alunos foi proposto que observassem os dados disponibilizados no blog da disciplina (prj062glaura.blogspot.com) e que, baseados na própria experiência durante a aplicação dos questionários, analisassem o distrito a partir dos aspectos que se mostraram mais relevantes para sua compreensão e quais situações incomuns ou contraditórias se revelaram.

Os tópicos referentes ao saneamento básico tiveram destaque nas análises, principalmente no que se refere ao abastecimento de água e aos problemas quanto à destinação do esgoto das casas. O gráfico apresentado na figura 3, por exemplo, mostra a relação entre as reclamações feitas pelos moradores sobre o abastecimento de água e a região do distrito onde moram. O Centro ou Casa Branca (denominações dadas à mesma região, onde fica o centro histórico do distrito), em comparação com as regiões mais periféricas, como o Campo e Soares, apresenta um percentual menor de reclamações. Uma possível explicação para isso passa pelos processos de ocupação da região, sendo que o Centro/Casa Branca tem ocupação mais antiga, enquanto Campo e Soares tiveram um crescimento notável nos últimos anos. No caso exemplificado, diversas questões podem ser levantadas, relacionando principalmente os problemas de infraestrutura identificados às regiões e ao processo de gentrificação, o que tende a aprofundar a compreensão sobre a percepção dos moradores no que 
concerne aquilo que se mostra relevante em seu cotidiano no distrito.

Como a quantidade de dados levantados foi bastante expressiva, ficou claro que o tratamento quantitativo simples já aponta uma diversidade de possibilidades para análise qualitativa do distrito. Contudo, o recurso de cruzamento dos dados no SPSS permite um grande avanço na direção da análise qualitativa de dados quantitativos, mesmo que as tabelas e gráficos gerados possam ser muito melhorados se considerarmos as diretrizes de Tufte (1983). No caso de Glaura, a intenção com o SPSS é que a partir dos questionamentos gerados pelo gráfico de um cruzamento, outros cruzamentos sejam buscados para complementar as informações, e que, com isso, seja elaborada uma análise sócio-espacial qualitativa da comunidade por meio de dados quantitativos. Esse processo está ainda em andamento, sendo que as primeiras análises já foram feitas e novos cruzamentos de dados estão sendo gerados para aprofundar a análise do distrito.

\section{Teoria ator rede}

Paralelamente à análise do distrito por meio dos cruzamentos gerados no SPSS, buscamos também complementar o entendendimento da complexidade das relações sócio-espaciais adotando a Teoria Ator-Rede (LATOUR, 2005). Essa teoria enfatiza a ideia de que as relações sociais são formadas por atores humanos e não humanos em rede, sendo que cada ator constitui também uma rede (LAW, 2016). Assim, as relações entre atores são vistas de forma heterogênea, mas não absoluta nem relativa, ou seja, não há determinismo estrutural ou tecnológico e nem determinismo social, mas também não há relação direta de causa-efeito entre atores. Segundo Bruno Latour (2005) o agenciamento emerge das relações entre todos os atores, sem que um deles em específico esteja no comando.

Tal teoria parte do pressuposto que para entender a mecânica do poder e da organização de uma rede não se deve recorrer a concepções prévias de relações de poder que naturalizam as relações sociais, pois isso tira de cena questionamentos importantes para a compreensão de como a organização é gerada. Dessa forma, deve-se começar assumindo que a interação entre os atores é tudo que há e que nenhum ator, seja ele pessoa ou artefato, determina, a priori, a "mudança ou a estabilidade social, em geral" (LAW, 2016). Ao fim e ao cabo, a Teoria Ator-Rede tende a dar voz a todos os atores para então entender como o agenciamento acontece na rede.

Por exemplo, Glaura é uma rede constituída por algumas regiões que são consideradas atores. Entretanto, cada região é composta também por uma rede com diversos outros atores, fazendo com que as relações entre eles não se resumam à articulação entre regiões. Assim, a rede criada pela conexão entre todos os atores revela a complexidade da cena de Glaura e possibilita uma compreensão ampla da dinâmica que mantém unidos os elementos heterogêneos que a constituem.

Para a construção da rede de Glaura listamos os principais atores por meio de um brainstorming que teve como base as informações levantadas nas entrevistas semi-estruturadas.
Isso foi produtivo para o levantamento dos atores, mas na formulação da rede ficou evidente a dificuldade de não prefigurar relações de poder a partir de nossos préjulgamentos, nem reduzir a complexidade da formulação da rede. No intuito de superar tal dificuldade, seguindo as diretrizes da Teoria Ator-Rede, usamos o software GEPHI, que facilita a articulação de elementos entre si em diversas combinações possíveis.

O uso do GEPHI associado à Teoria Ator-Rede começou a ser desenvolvido pela equipe na disciplina optativa "Práticas espaciais e tecnologias digitais em comunidades rururbanas", ofertada em 2016 por Lorena Melgaço e Ana Paula Baltazar e sistematizada como possível método antropofágico para levantamento de dados urbanos (MELGAÇO e BALTAZAR, 2017). Essa associação consegue, a partir da interação entre elementos (nesse caso atores), formar redes extremamente complexas apresentando todas as relações possíveis, que podem ser valoradas ou não (podemos inserir pesos distintos para relações que consideramos mais ou menos fortes). Além disso, ele possibilita, por meio de algoritmos, o estabelecimento de análises automáticas da rede criada.

Adotamos inicialmente combinações dos atores sem atribuição de valor. Dentre as análises que o programa oferece, utilizamos duas que se mostraram mais eficazes para o que julgamos importante observar: a primeira foi criar agrupamentos, ou sub-redes, dentro da rede mais ampla de Glaura e a segunda foi evidenciar os atores que possuem mais conexões. Dessa forma, partindo de uma cena complexa e muito ampla é possível dar enfoque de acordo com o tema que se deseja abordar, sem prefigurar relações de poder de antemão.

Para analisar a questão do saneamento básico, por exemplo, podemos destacar o agrupamento dos atores que estão relacionados a esse tema (como por exemplo, "sitiantes", "associação glaura", "rio" etc.), sem, entretanto, perder a relevância do contexto geral, uma vez que toda a rede permanece visível. Já o segundo tipo de análise possibilita entender quem ou o quê são os atores protagonistas dessas relações sociais. Em outras palavras podemos compreender assuntos pontuais sem ignorar o fato de que cada assunto está conectado a outro numa rede extremamente complexa.

Os agrupamentos ou sub-redes que o GEPHI faz são apresentados por meio das cores, enquanto a importância que determinado ator tem na rede, ou seja, a quantidade de ligações que ele tem com outros é representada pelo tamanho tanto da fonte quanto do círculo, como pode ser notado na figura 4. 


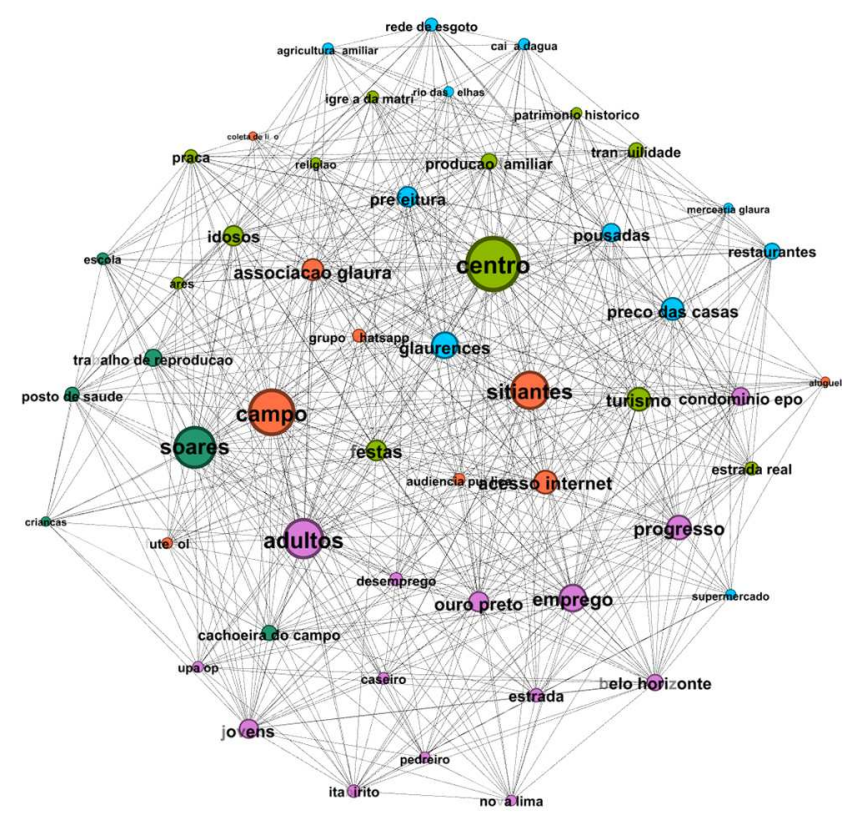

Figura 4. Rede elaborada para análise de Glaura.

A utilização do GEPHI permitiu a aplicação da Teoria AtorRede de forma eficaz, pois a importância de cada ator não é estabelecida por uma pessoa, com todos os seus valores e pré-conceitos, mas sim pela posição e pelas ligações que esse ator estabelece na rede, uma vez que a sistematização é feita pelo próprio software. Logo, são evidenciadas relações que talvez não seriam feitas se a sistematização dependesse de uma pessoa, e que, conforme pudemos observar em outros casos e no caso de Glaura, apresentaram um panorama bastante real da comunidade. Assim, é possível que a análise sócio-espacial se paute com mais ênfase nas informações trazidas pelos moradores, evitando as interferências dos pressupostos do pesquisador.

\section{Considerações finais}

Durante o processo do levantamento sócio-espacial, os softwares Formulários Google, SPSS e GEPHI se mostraram muito importantes para a agilidade na compilação $e$ processamento de dados. Apesar de não termos conclusões gerais sobre a utilização desses softwares em pesquisas qualitativas e das dificuldades que surgiram no uso, muitas vezes causadas pela falta de conhecimento e costume com os programas, os dados que levantamos a partir do uso de tais softwares nos proporcionaram uma visão bastante aprofundada do contexto sócio-espacial de Glaura. Desta maneira, apontamos para um método que se beneficia de um conjunto de ferramentas multidisciplinares, qualitativas e quantitativas, para coletar informações complexas que alimentarão a pesquisa e consequentemente informarão a produção de interfaces voltadas para a comunidade nas próximas etapas de desenvolvimento do método de assessoria técnica de arquitetura e urbanismo em Glaura.

\section{Agradecimentos}

Os autores agradecem à FAPEMIG, CAPES, CNPq, FINEP e Pró-Reitorias de Pesquisa e de Extensão da UFMG, pelas bolsas e financiamentos às pesquisas, e aos alunos da disciplina Tópicos em Teoria de Projetos Levantamento sócio-espacial em Glaura no primeiro semestre de 2017, pela participação na aplicação dos questionários e análises.

\section{Referências}

Arendt, Hannah. A Condição Humana. Rio de Janeiro: Forense Universitária, 2011 [1958].

Baltazar, Ana Paula e Kapp, Silke. Assessoria técnica com interfaces. IV ENANPARQ: Encontro da Associação Nacional de Pesquisa e Pós-Graduação em Arquitetura e Urbanismo. Porto Alegre, 25 a 29 de julho de 2016.

Brasil. Lei 11.888, de 24 de dezembro de 2008. Assegura às famílias de baixa renda assistência técnica pública e gratuita para o projeto e a construção de habitação de interesse social e altera a Lei no 11.124, de 16 de junho de 2005. <http://www.planalto.gov.br/ccivil_03/_Ato20072010/2008/Lei/L11888.htm>

Illich, Ivan. Needs. Manuscrito não terminado e não publicado. Bremen, 1990.

Illich, Ivan. To hell with good intentions. 1968. <http://www.swaraj.org/illich_hell.htm>

Kapp, Silke; Baltazar, Ana Paula; Campos, Rebekah; Magalhães, Pedro; Milagres, Lígia; Nardini, Patrícia; Olyntho, Bárbara; Polizzi, Leonardo. Arquitetos nas favelas: três críticas e uma proposta de atuação. In: Anais do CTHab 2012 - IV Congresso Brasileiro e III Congresso Ibero-Americano Habitação Social: ciência e tecnologia - Inovação e Responsabilidade. Florianópolis: PósARQ/UFSC e ACE/SC, 2012.

Kapp, Silke and Baltazar, Ana Paula. The Paradox of Participation: a case study on urban planning in favelas and a plea for autonomy. In: Bulletin of Latin American Research, Journal of the society for Latin American Studies (Special Issue: The Urban Divide in Latin America: Challenges and Strategies for Social Inclusion, Guest Edited by Joseli Macedo), Oxford: Wiley-Blackwell, 2012. pp, 160-173.

Latour, Bruno. Reassembling the social - an Introduction to ActorNetwork-Theory. Oxford: OUP, 2005.

Law, John. Notas sobre a teoria do ator-rede: ordenamento, estratégia, e heterogeneidade. Tradução Fernando Manso. <http://www.necso.ufrj.br/Trads/Notas\%20sobre\%20a\%20teoria \%20Ator-Rede.htm>

Melgaço, Lorena e Baltazar, Ana Paula. Anthropophagy In Planning: Building A Theory From The South Through An Association Of Actor-Network Theory And Historical Materialism. Proceedings of Lisbon AESOP Annual Conference: Spaces of Dialogue for Places of Dignity. Lisbon, 11-14 July 2017.

Pogrebinschi, Thamy. O enigma do político: Marx contra a política moderna. Rio de Janeiro: Civilização Brasileira, 2009.

Souza, Jessé. A ralé brasileira: quem é e como vive. Belo Horizonte: Editora UFMG, 2009.

Tufte, Edward. Visual display of quantitative information. Graphics Press LLC, 1983. 